\title{
Profile and role of immune function changes of $T$ lymphocytes in patients with acute pancreatitis
}

\author{
Qi WANG ${ }^{1 *}(\mathbb{D})$, Shaofeng LIU ${ }^{1}$, Zhen HAN ${ }^{1}$
}

\begin{abstract}
In recent decades, with the development of the pathogenesis of Acute severe pancreatitis (SAP) and the improvement of clinical treatment techniques, the mortality rate of SAP is still over $10 \%$. Recent studies have shown that immune dysregulation plays an important role in the pathogenesis of AP, especially in SAP. A meta-study points to widespread concern for the discovery of immunosuppression by networked cytokines in the course of AP. In the early stages of AP, high cytokine levels play a leading role in the development of SIRS pathological conditions, which result in a cascade of inflammatory cytokines that induce the release of immunocompetent cells, leading to an excessive immune response. In the later stages of Compensatory anti-inflammatory response syndrome (CARS), the body over-releases anti-inflammatory agents and has an immunosuppressive process, but contributes to the development of the risk of secondary infection and increases the likelihood of Multiple organ disfunction syndrome (MODS). The study was aimed to measure T-lymphocyte immune function changes of patients with acute pancreatitis and to explore BISAP scoring system in clinical applications.
\end{abstract}

Keywords: acute pancreatitis; bedside index for severity in acute pancreatitis; CD4+CD25+CD127+ Treg; T lymphocyte.

Practical Application: CD4+CD25+CD127+Treg probably plays an immunosuppressive role by promoting the secretion of IL-4. During the SIRS phase, the quantity of CD4+CD25+CD127+Treg in the SAP patients is significantly higher than that in the MAP patients.

\section{Introduction}

Acute pancreatitis (AP) is a common disease. With the global economic level and dietary structure changes, high-sugar and high-fat diets greatly increase the incidence of AP (Zheng et al., 2021).Metabolic risk factors such as obesity and hyperlipidemia are independent risk factors for the occurrence of various complications of AP.Hyperglycemia plays an important role in the development of AP (Nagy et al., 2021). During which the destruction of pancreatic parenchyma initially induces topical inflammatory reaction, but it may lead to a large number of inflammatory mediators and early organ failure. Anti-inflammation cytokines and specific cytokine inhibitors are also interlocked, which probably overreacts, inhibits the immune system and increases the risk of systemic infection.

AP generally goes through two stages: systemic inflammatory response syndrome (SIRS) and compensatory anti-inflammatory response syndrome (CARS) stages. In the course of AP, immune stress and immunosuppression may coexist in sequence and become unbalanced alternately. During the CARS stage, the number of peripheral blood lymphocytes is significantly decreased, and the levels of pro-inflammatory and anti-inflammatory cytokines are also decreased to maintain the immune response. T lymphocytes play a central role in the specific immune function of the host body. At present, clinical studies have shown that the cellular immune function of the host body decreases when AP occurs, and the number of $\mathrm{CD} 3+, \mathrm{CD} 4+, \mathrm{CD} 8+\mathrm{T}$ cells and $\mathrm{CD} 4+/ \mathrm{CD} 8+$ ratio

are declined in the peripheral blood of patients, thereby leading to severe infection in the advanced stage (Pietruczuk et al., 2006).

CD4+CD25+CD127+Treg is a lymphocyte subset with negative immunoregulation effect (Kylänpää et al., 2010), which is an important subset of $\mathrm{T}$ cell-mediated peripheral immune tolerance. $\mathrm{CD} 4+\mathrm{CD} 25+\mathrm{CD} 127+$ Treg can avoid the autoimmune diseases and allergic reactions. Besides, it can inhibit the anti-tumor and pathogen immune response of the host. In SIRS stage of AP, $\mathrm{CD} 4+\mathrm{CD} 25+\mathrm{CD} 127+$ Treg activity in the body is significantly increased, which can inhibit the production of pro-inflammatory cytokines induced by Toll-like receptor (TLRs) (Zhao et al., 2011).

Peripheral blood mononuclear cells (PBMCs) also plays a pivotal role during the occurrence and development of AP. PBMCs are able to bind to chemokines produced by inflammatory sites through its receptors, and then activated by PBMC to promote local inflammatory reactions. PBMCs also participate in the SIRS reactions through other inflammatory cells and cytokines, such as interleukin (IL)-6 and IL-12, etc. Jani Oival et al. (Oiva et al., 2010) have demonstrated that incompetent PBMCs exist in AP patients. Since PBMCs can secrete a large amount of pro-inflammatory factor TNF- $\alpha$, and then the quantity of TNF- $\alpha$ is reduced (Döcke et al., 1997). Among the peripheral blood cells, PBMCs can express the highest level of CD14. In the early stage of AP, the expression level of CD14 in PBMCs does not significantly alter. When the course of disease is longer than 1 week, 
the $\mathrm{CD} 14$ expression restores to normal level and subsequently declines (Li et al., 2007). Götzinger et al. (Götzinger et al., 2000) found that CD14 expression is down-regulated in the early stage of AP. However, some studies have shown that the expression of CDI4 and TLR4 as lipopolysaccharides (LPS) receptors is up-regulated in the animal rat models of alcoholic chronic pancreatitis (Pan et al., 2012). CD14 is a multifunctional highaffinity receptor for endotoxin, LPS and cell wall components of other bacteria. The low expression level of CD14 indicates that the patient is in an immunosuppressive state and the clinical prognosis is poor, whereas the high level of CD14 expression predicts that the patient is in an immune hyperfunction state.

The role of neutrophils (PMN) has been constantly neglected in the recent studies of AP pathogenesis. CARS stage inhibits the immune system and promotes the nosocomial infection of patients, including infectious pancreatic necrosis, which is also one of the most severe complications. A majority of SAP infected bacteria originate from the intestine (McNaught et al., 2002). The neutrophil CD64 is a reliable indicator in the diagnosis of bacterial infection (Cid et al., 2010). CD64 is one of IgG Fc segment receptors and belongs to immunoglobulin superfamily. CD64 is mainly distributed on the surface of antigen-presenting cells, such as activated PMN, macrophages and dendritic cells, and is generally expressed at a low level (Fossati et al., 2001). Li et al. (Li et al., 2007) have demonstrated that in SAP patients, phagocytosis and sterilization function of PMN are decreased in the early stage and cellular immune function is obviously impaired. In the present study, whether the expression levels of PMN and CD64 on its surface are correlated with the pathogenesis of AP immunity was explored.

During the process of AP, various immune cells migrate to the inflammatory site to assist and transform into activated effector immune cells to play an immune role. A large number of apoptotic cells die, thus significantly reducing the body's immune function. There are still controversies about the specific pathogenesis and signal transduction signaling pathway of immune disorders. In this investigation, the immune function changes of T lymphocytes in AP patients in acute pancreatitis (BISAP) score was investigated aiming to preliminarily explore the role of various immune cells in the pathogenesis of AP.

\section{Materials and methods}

\subsection{Baseline data}

Forty patients with AP admitted to the Department of Gastroenterology of Yijishan Hospital of Wannan Medical College from November 2011 to December 2012 were recruited in this investigation. Twenty healthy subjects, matched with sex and age, were enrolled in the control group. All healthy controls have no surgical history and obtain normal results for routine blood test, biochemical test, urine test, electrocardiogram and abdominal ultrasound. According to the BISAP score, $40 \mathrm{AP}$ patients were divided into the severe acute pancreatitis (SAP, $n=20$ ) and mild acute pancreatitis (MAP, $n=20$ ) groups. A portion of $5 \mathrm{~mL}$ of fasting peripheral blood samples were collected from AP patients and healthy controls at 7 a.m., and placed into the 90USP heparin sodium tubes, fully oscillated and mixed to avoid the peripheral blood coagulation. The study procedures were approved by the ethics committee of the First Affiliated Hospital of Wannan Medical College Yijishan Hospital. Written informed consents were obtained from all participants prior to study.

\subsection{Inclusion and exclusion criteria}

Inclusion criteria: All patients were diagnosed with acute pancreatitis according to the 2004 Chinese guidelines for the diagnosis and treatment of acute pancreatitis (Pancreas Disease Group of Digestive Disease Branch of Chinese Medical Association, 2013). All patients were evaluated by the BISAP scored and divided into the SAP (BISAP score $\geq 3$ ) and MAP (BISAP score $<3$ ) groups. Exclusion criteria: those diagnosed with pancreatic or peri-pancreatic infection, pregnant or breast-feeding women, cancer patients. All enrolled AP patients and healthy controls denied the medical history of dysfunction of heart, lung, brain, liver, kidney and other vital organs, immune deficiency disease, autoimmune disease, drug allergy, surgical trauma and blood transfusion in the past 3 months.

\subsection{CD4+CD25+CD127+Treg detection}

Three test tubes were added with corresponding antibodies in the dark room. Blank tube: no antibody was added as blank control; control tube: $5 \mu \mathrm{L}$ of FITC-IgG1 $+5 \mu \mathrm{L}$ PE-IgG1; Treg tube: $10 \mu \mathrm{L}$ of CD4-FITC + $10 \mu \mathrm{L}$ CD25-PC5 + $10 \mu \mathrm{L}$ CD127-PE. After the antibody labeling, $50 \mu \mathrm{L}$ of the whole blood was supplemented to each tube, stirred and mixed evenly, incubated at room temperature in dark room for 20 minutes, $1 \mathrm{~mL}$ of flow cytometry lysing solution was added, stirred and mixed evenly, reacted in dark room for 5 minutes, and the cells were fully suspended with $1 \mathrm{ml}$ of phosphate buffer saline (PBS), and detected by flow cytometer.

\section{$2.4 C D 3+, C D 4+, C D 8+$ expression in $T$ lymphocyte subsets}

Two test tubes were added with corresponding antibodies in the dark room. Control tube: $5 \mu \mathrm{L}$ of FITC-IgG1 $+5 \mu \mathrm{L}$ PE-IgG1; T cell subset tube: $10 \mu \mathrm{L}$ of CD45-FITC $+10 \mu \mathrm{L}$ of CD4-PE+10 $\mu \mathrm{L}$ of $\mathrm{CD} 8-\mathrm{ECD}+10 \mu \mathrm{L}$ of CD3-PC5. After the antibody labeling, $50 \mu \mathrm{L}$ of the whole blood was added to each tube, stirred and mixed evenly, incubated at room temperature in the dark for 20 minutes, $1 \mathrm{~mL}$ of flow cytometry lysing solution was supplemented, stirred and mixed evenly, reacted at dark for 5 minutes, washed with $2 \mathrm{~mL}$ of PBS, centrifuged at $20^{\circ} \mathrm{C}$ for $1500 \mathrm{rpm}$ for 5 minutes, and the supernatant was discarded. A portion of $2 \mathrm{~mL}$ of PBS was used to irrigation, and then centrifuged at $20^{\circ} \mathrm{C}$ for $1500 \mathrm{rpm}$ for 5 minutes, and the supernatant was discarded. Cells were fully suspended in $1 \mathrm{~mL}$ of PBS and prepared for flow cytometry.

\subsection{CD14+ PBMN and CD64+PMN detection}

Three test tubes were supplemented with corresponding antibodies in the dark room. Blank tube: no antibody was added as blank control; Control tube: FITC-IgG1+5 $\mu \mathrm{L}$ PE-IgG1; CD14+/ CD64+ tube: $10 \mu \mathrm{L}$ CD45-PC5 + $10 \mu \mathrm{L}$ CD14-PE + $10 \mu \mathrm{L}$ CD64FITC. After the antibody labeling, $50 \mu \mathrm{L}$ of the whole blood was added to each tube, stirred and mixed evenly, incubated at room temperature in dark for 20 minutes, $1 \mathrm{~mL}$ of flow cytometry lysing solution was added, stirred and mixed evenly, reacted at dark room for 
5 minutes, washed with $2 \mathrm{ml}$ of PBS, centrifuged at $20^{\circ} \mathrm{C}$ for $1500 \mathrm{rpm}$ for 5 minutes, and the supernatant was discarded. Add irrigation with $2 \mathrm{~mL}$ PBS, the cells were centrifuged at $20^{\circ} \mathrm{C}$ for $1500 \mathrm{rpm}$ for 5 minutes, the supernatant was discarded, fully suspended the cells with $1 \mathrm{~mL}$ PBS buffer and detect by flow cytometry.

\subsection{Detection of IL-10 and IL-4 in peripheral blood by ELISA}

The human IL-10 quantitative EIA kit or IL-4 quantitative EIA kit was diluted with redistilled water at a ratio of $1: 20$, the blood sample was centrifuges for at $1500 \mathrm{rpm}$ for 10 minutes, the serum was extracted, frozen at $-80^{\circ} \mathrm{C}$. The sample was collected and thawed. A portion of $100 \mu \mathrm{L}$ of sample diluent was added to each well, $100 \mu \mathrm{L}$ of standard solution was added to the first well, and $100 \mu \mathrm{L}$ of the solution was added to the second well. After the dilution was repeated to the 7 th well, $100 \mu \mathrm{L}$ of solution was collected and discarded from the 7 th well to maintain the volume of $100 \mu \mathrm{L}$. The 8 th well was used as the blank control. A portion of $100 \mu \mathrm{L}$ of the sample was supplemented to each well, mixed evenly and then placed at $37^{\circ} \mathrm{C}$ for 120 minutes, the reaction plate was fully washed for 4 times, except for blank holes. The first antibody working solution was added to each well, placed at $37^{\circ} \mathrm{C}$ for 60 minutes, the reaction plate was fully washed for 4 times, except for blank holes, $100 \mu \mathrm{L}$ of enzyme labeled antibody working solution was added to each well, placed at $37^{\circ} \mathrm{C}$ for 60 minutes, $100 \mu \mathrm{L}$ of substrate $\mathrm{TMB}$ was added to each well, and the reaction was carried out in the dark at $37^{\circ} \mathrm{C}$ for 5 minutes. A portion of $50 \mu \mathrm{L}$ of termination solution was added to each well and mixed evenly. The expression level of IL-10 and IL- 4 content were detected according to the optical density (OD) values.

\subsection{Statistical analysis}

All data analyses were performed by SPSS16.0 statistical software (SPSS Inc., Chicago, IL, U.S.). The measurement data were expressed as mean \pm standard deviation (SD). After normal test and variance homogeneity test, the expression rates of CD4+CD25+CD127+ Treg, CD14+ PBMC, CD3+, CD4+, CD8+ T lymphocyte subsets and IL-10 and IL-4 in the peripheral blood were analyzed by one-way ANOVA. The expression rate of CD64+ PMN was analyzed by rank sum test. A P value of less than 0.05 was considered as statistical significance.

\section{Results}

\subsection{Baseline data}

Among 40 AP patients, 17 cases were male (aged 54.6 years old on average) and 23 female (aged 51.2 years old on average), aged from 25 to 86 years with a mean age of $(52.9 \pm 16.5)$ years. According to the BISAP score, 20 AP patients (50\%) were evaluated as the MAP patients including 9 male and 11 female, aged $25-86$ years with an average age of $(45.7 \pm 17.3)$ years. Twenty cases (50\%) were classified as SAP patients, aged 33-86 years with a mean age of $(55.3 \pm 15.6)$ years. Seventeen AP patients were complicated with topical complications and 12 with systemic complications. Among 40 AP cases, 33 patients (82.5\%) were complicated with biliary AP, 6 patients (15\%) with acute lipogenic pancreatitis, and 1 case $(2.5 \%)$ with alcoholic pancreatitis.

\subsection{Expression of $\mathrm{CD}^{+} \mathrm{CD}^{+} 5^{+} \mathrm{CD} 127^{+}$Treg, $\mathrm{CD} 14^{+} \mathrm{PBMC}$, $\mathrm{CD}^{+} 4^{+} \mathrm{PMN}, \mathrm{CD3}^{+}, \mathrm{CD}^{+}$and $\mathrm{CD8}^{+} \mathrm{T}$ lymphocyte subsets}

The expression rates of $\mathrm{CD}^{+}$and $\mathrm{CD}^{+} \mathrm{T}$ lymphocyte subsets, CD $14^{+}$PBMCs in the MAP patients and SAP patients were $(57.22 \pm 13.40,33.95 \pm 8.79$ and $2.39 \pm 1.91)$ and $(54.73 \pm 10.79$, $32.95 \pm 13.49,2.07 \pm 1.06)$, respectively, significantly lower than $(71.55 \pm 9.07,42.00 \pm 8.10$ and $3.400 \pm 1.31)$ in the healthy controls (all $P<0.05$ ). The average rank orders of D $64^{+} \mathrm{PMNC}$ expression rates in the MAP and SAP patients were 39.8 and 37.6, significantly higher than 14.1 in the healthy controls. The expression rates of $\mathrm{CD}^{+}, \mathrm{CD}^{+} \mathrm{CD} 25^{+} \mathrm{CD} 127^{+}$Treg in the $\mathrm{T}$ lymphocyte subsets in MAP and SAP patients were $(29.33 \pm 21.94,1.11 \pm 0.71)$ and $(26.13 \pm 11.18,3.16 \pm 3.67)$, which did not significantly differ compared with that in the healthy control group (both $P>0.05)$. The $\mathrm{CD}^{+} / \mathrm{CD}^{+}$ratios in the SAP and MAP patients were $(1.28 \pm 0.57,1.58 \pm 0.75)$ with no statistical significance compared with $(1.78 \pm 0.53)$ in the healthy controls (both $P>0.05)$. The expression rate of $\mathrm{CD} 4^{+} \mathrm{CD} 25^{+} \mathrm{CD} 127^{+}$Treg significantly differed between the MAP $(1.11 \pm 0.71)$ and SAP patients $(3.16 \pm 3.67)$ $(P<0.01)$, other indexes did not significantly differ between two groups (all $P>0.05$ ), as illustrated in Figures 1-3, Tables 1-3.

Table 1. Comparison of $\mathrm{CD}^{+}, \mathrm{CD}^{+}$and $\mathrm{CD} 8^{+} \mathrm{T}$ lymphocytes subsets among different groups (\%, $\bar{x} \pm \mathrm{s})$.

\begin{tabular}{cccc}
\hline Group $(\mathrm{n}=20)$ & $\mathrm{CD}^{+}(\%)$ & $\mathrm{CD} 4^{+}(\%)$ & $\mathrm{CD}^{+}(\%)$ \\
\hline Control group & $71.55 \pm 9.07^{\mathrm{a}}$ & $42.00 \pm 8.10^{\mathrm{a}}$ & $25.05 \pm 5.98$ \\
SAP group & $54.73 \pm 10.79^{\mathrm{b}}$ & $32.95 \pm 13.49^{\mathrm{b}}$ & $26.13 \pm 11.18$ \\
MAP group & $57.22 \pm 13.40^{\mathrm{b}}$ & $33.95 \pm 8.79^{\mathrm{b}}$ & $29.33 \pm 21.94$ \\
$F$ & 13.066 & 4.537 & 0.464 \\
$P$ & 0.000 & 0.015 & 0.631 \\
\hline
\end{tabular}

SNK-q test was used for comparison between the two groups; Different letters indicate $P<0.05$ between the two groups, and the same letters represent $P>0.05$ between the two groups.

Table 2. Comparison of TregCD $4^{+} \mathrm{CD} 25^{+} \mathrm{CD} 127^{+}, \mathrm{CD} 14^{+} \mathrm{PBMCs}$ and $\mathrm{CD}^{+} / \mathrm{CD}^{+}$ratio among different groups $(\bar{x} \pm \mathrm{s})$.

\begin{tabular}{cccc}
\hline Group $(\mathrm{n}=20)$ & $\begin{array}{c}\mathrm{CD} 4^{+} \mathrm{CD} 25^{+} \\
\mathrm{CD} 127^{+} \text {Treg }(\%)\end{array}$ & $\mathrm{CD}^{+} / \mathrm{CD} 8^{+}$ & ${\mathrm{CD} 14^{+}(\%)}^{\mathrm{ab}}$ \\
\hline Control group & $2.15 \pm 0.96^{\mathrm{b}}$ & $1.78 \pm 0.53$ & $3.40 \pm 1.31^{\mathrm{a}}$ \\
SAP group & $3.16 \pm 3.67^{\mathrm{bc}}$ & $1.28 \pm 0.57$ & $2.07 \pm 1.06^{\mathrm{b}}$ \\
MAP group & $1.11 \pm 0.71^{\mathrm{a}}$ & $1.58 \pm 0.75$ & $2.39 \pm 1.91^{\mathrm{b}}$ \\
$F$ & 4.257 & 3.139 & 4.488 \\
$P$ & 0.019 & 0.051 & 0.015 \\
\hline
\end{tabular}

SNK-q test was used for comparison between the two groups; Different letters indicate $P<0.05$ between the two groups, and the same letters represent $P>0.05$ between the two groups.

Table 3. Comparison of CD64 ${ }^{+} \mathrm{PMN}$ among different groups $(\bar{x} \pm \mathrm{s})$.

\begin{tabular}{cc}
\hline Group $(\mathrm{n}=20)$ & $\begin{array}{c}\mathrm{CD} 64^{+}(\%) \\
\text { Mean rank order }\end{array}$ \\
\hline Control group & $14.1^{\mathrm{a}}$ \\
SAP group & $37.6^{\mathrm{b}}$ \\
MAP group & $39.8^{\mathrm{b}}$ \\
$X^{2}$ & 26.621 \\
$P$ & 0.000 \\
\hline
\end{tabular}

Mann-Whitney $U$ test was used for comparison between two groups; Kruskal Wallis test was utilized comparison among three groups; Different letters indicate $P<0.05$ between the two groups, and the same letters represent $P>0.05$ between the two groups. 

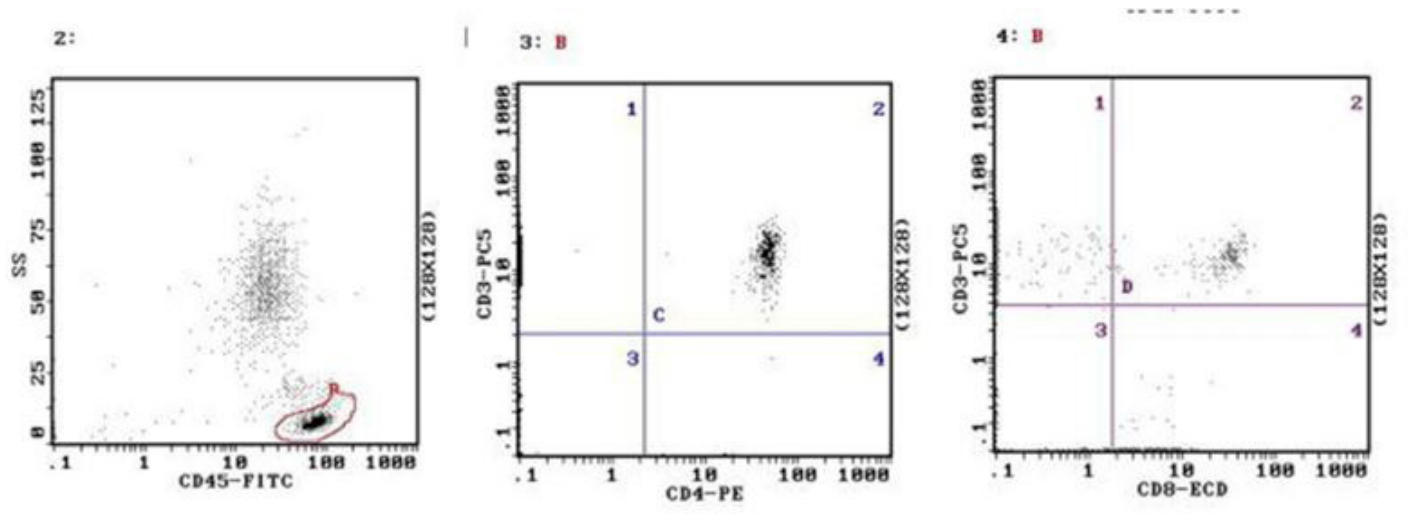

A

B
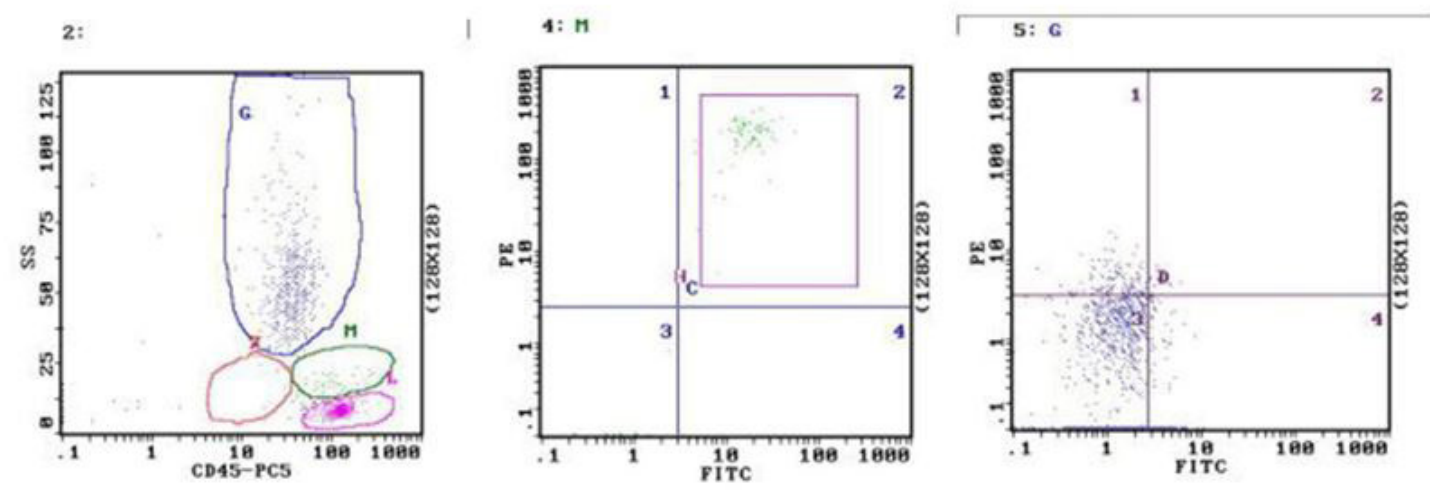

D

E
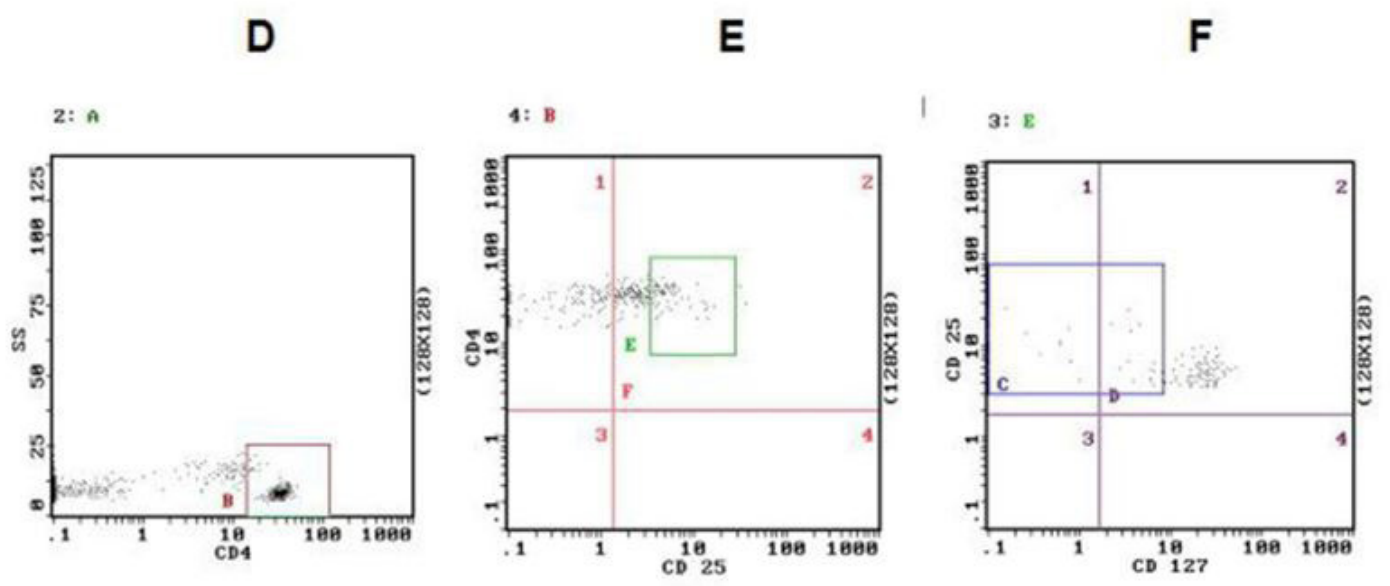

G

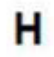

Figure 1. Flow cytometry of $\mathrm{CD} 4^{+} \mathrm{CD} 25^{+} \mathrm{CD} 127^{+}$Treg, $\mathrm{CD} 14^{+} \mathrm{PBMC}, \mathrm{CD} 64^{+} \mathrm{PMN}, \mathrm{CD} 3^{+}, \mathrm{CD}^{+}$and $\mathrm{CD} 8^{+} \mathrm{T}$ lymphocyte subsets in healthy controls. (A) Gating for T lymphocytes; (B) CD3 ${ }^{+} \mathrm{CD} 4 \%$ \%:22.4\%; (C) $\mathrm{CD}^{+}{ }^{+} \mathrm{CD} 8 \%$ \%:14.72\%; (D) Gating for CD $45^{+}$cells; (E) CD14 ${ }^{+} \mathrm{PBMC} \%: 4.29 \%$; (F) CD64+ PMN\%:6.11\%; (G) Gating for CD4 ${ }^{+}$lymphocytes; (H) CD4 ${ }^{+} \mathrm{CD} 25^{+} \%: 8.16 \%$; (I) TregCD $4^{+} \mathrm{CD} 25^{+} \mathrm{CD} 127^{+} \%: 2.45 \%$.

\subsection{Inverted proportion of $\mathrm{CD}^{+} / \mathrm{CD}^{+}$ratio among different groups}

Although the ratio of $\mathrm{CD} 4^{+} / \mathrm{CD}^{+}$was affected by region, age, sex, etc., the ratio of $\mathrm{CD}^{+} / \mathrm{CD}^{+}$was normally ranged between 1.5 and 2.5. The inverted proportion was defined if the $\mathrm{CD}^{+} / \mathrm{CD}^{+}$ratio was less than 1 . The ratio of $\mathrm{CD}^{+} / \mathrm{CD}^{+}$was above 1 in $95 \%$ of the healthy population. Merely a minority of individuals presented with the inverted proportion of $\mathrm{CD}_{4}^{+} /$ $\mathrm{CD}^{+}$ratio. The proportion of $\mathrm{CD} 4^{+} / \mathrm{CD}^{+}$ratio $<1.5$ and the inverted proportion of $\mathrm{CD}^{+} / \mathrm{CD}^{+}$ratio in the MAP and SAP patients were $(60 \%, 20 \%)$ and $(60 \%, 40 \%)$, significantly higher than $(30 \%, 5 \%)$ in the healthy controls. The inverted proportion of $\mathrm{CD}^{+} / \mathrm{CD}^{+}$ratio in the SAP patients was $40 \%$, considerably higher than $20 \%$ in the MAP counterparts (Table 4 ). 


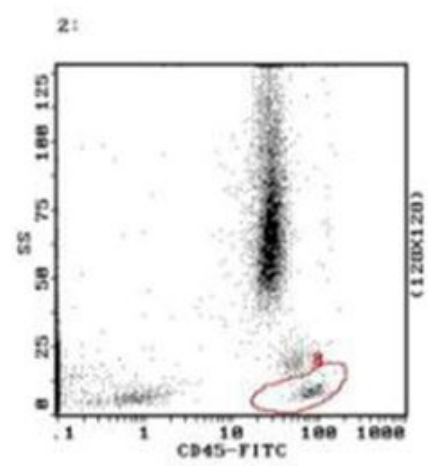

A

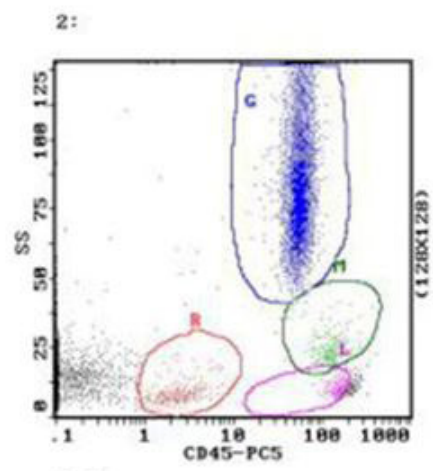

D

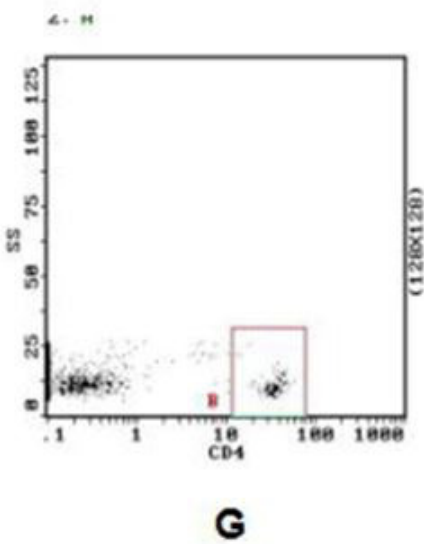

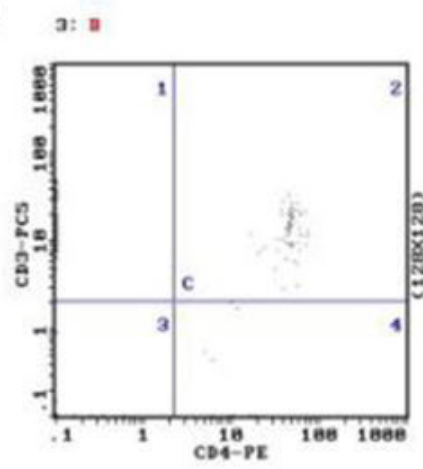

B 1 4: $\mathrm{m}$

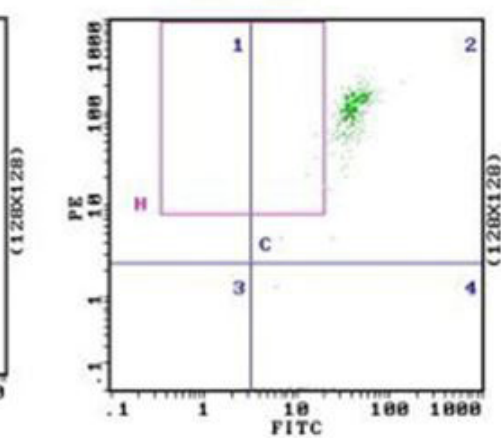

E

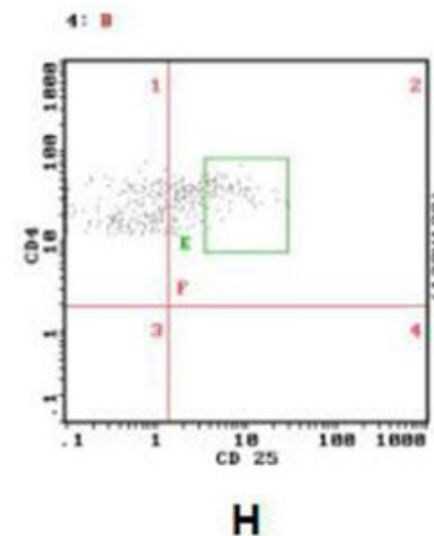

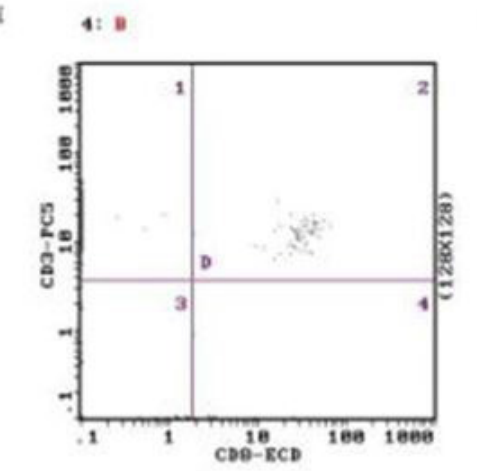

C

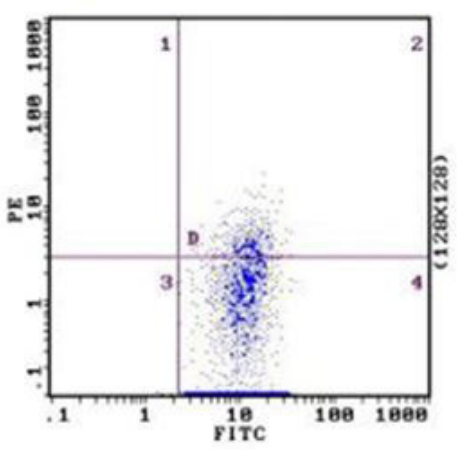

F

3: $x$

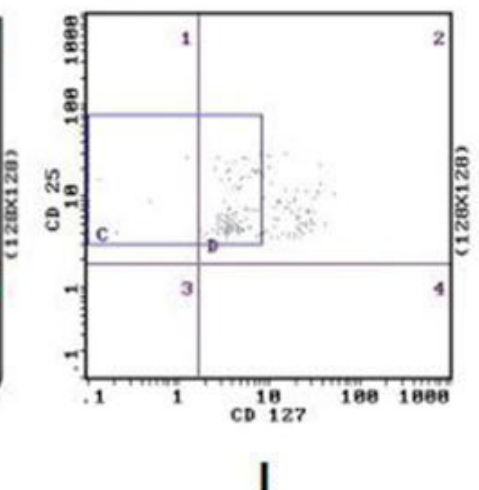

Figure 2. Flow cytometry of $\mathrm{CD} 4{ }^{+} \mathrm{CD} 25^{+} \mathrm{CD} 127^{+}$Treg, CD14+ $\mathrm{PBMC}, \mathrm{CD} 64^{+} \mathrm{PMN}, \mathrm{CD} 3^{+}, \mathrm{CD}^{+}$and $\mathrm{CD} 8^{+} \mathrm{T}$ lymphocyte subsets in $\mathrm{MAP}$ patients. (A) Gating for T lymphocytes; (B) $\mathrm{CD}^{+} \mathrm{CD} 4 \%: 13 \%$; (C) $\mathrm{CD}^{+}{ }^{+} \mathrm{CD} 8 \%: 11.96 \%$; (D) Gating for CD $45^{+}$cells; (E) CD14 ${ }^{+} \mathrm{PBMC} \%: 1.75 \%$; (F) CD64+ PMN\%:44.25\%; (G) Gating for CD4 $4^{+}$lymphocytes; (H) CD $4^{+} \mathrm{CD} 25^{+} \%: 1.99 \%$; (I) TregCD $4^{+} \mathrm{CD} 25^{+} \mathrm{CD} 127^{+} \%: 1.75 \%$.

Table 4. Comparison of inverted proportion of $\mathrm{CD} 4^{+} / \mathrm{CD}^{+}$ratio among different groups.

\begin{tabular}{cccccc}
\hline & Group $(\mathrm{n}=20) \mathrm{CD}^{+} / \mathrm{CD}^{+}$ratio $<1.5<1$ & $\mathrm{n} 1(\%)$ & $\mathrm{n} 2(\%)$ \\
\hline Control group & $\mathrm{n}$ & $\mathrm{n} 1$ & 1 & 30 & 5 \\
SAP group & 20 & 6 & 8 & 60 & 40 \\
MAP group & 20 & 12 & 4 & 60 & 20 \\
\hline
\end{tabular}




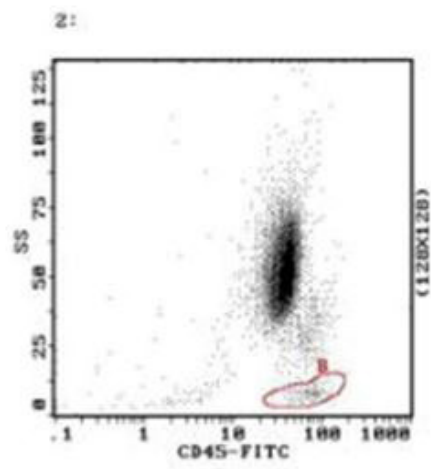

A

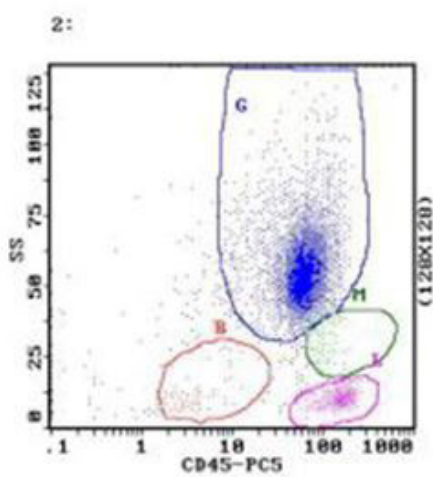

D

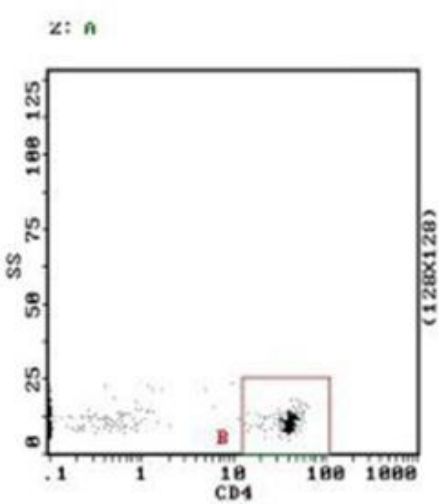

G

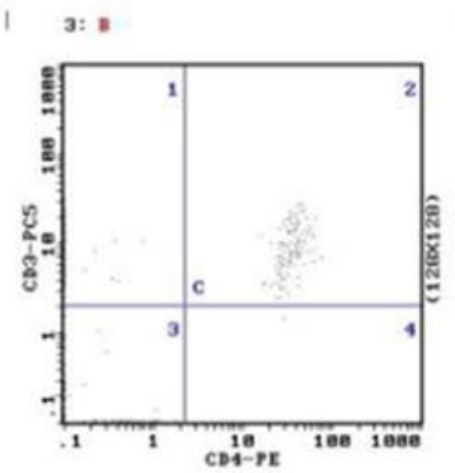

B 1 $1: n$

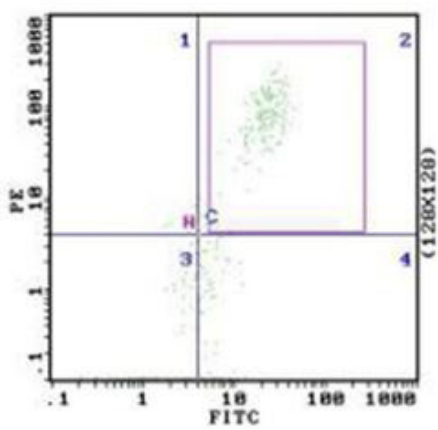

E

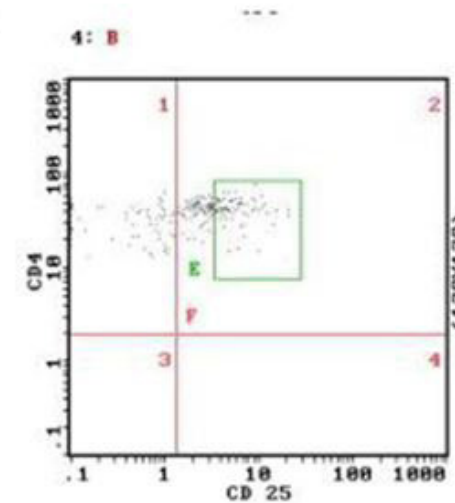

1

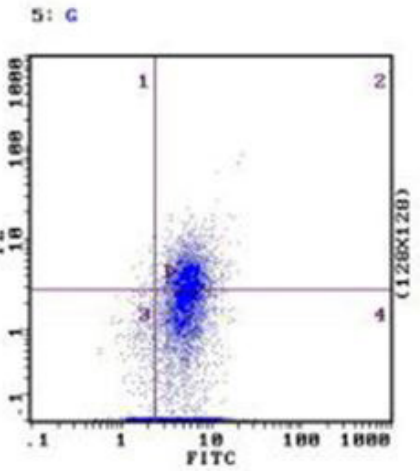

$\mathbf{F}$

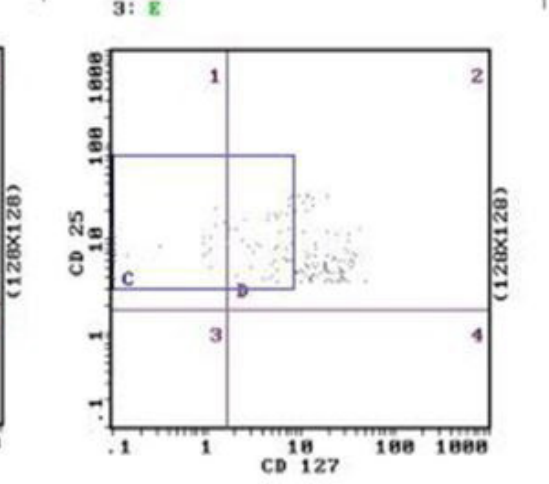

H

I

Figure 3. Flow cytometry of $\mathrm{CD} 4^{+} \mathrm{CD} 25^{+} \mathrm{CD} 127^{+}$Treg, $\mathrm{CD} 14^{+} \mathrm{PBMC}, \mathrm{CD} 64^{+} \mathrm{PMN}, \mathrm{CD}^{+}, \mathrm{CD}^{+}$and CD $8^{+} \mathrm{T}$ lymphocyte subsets in SAP patients. (A) Gating for T lymphocytes; (B) CD3 ${ }^{+} \mathrm{CD} 4 \%: 24.4 \%$; (C) $\mathrm{CD}^{+} \mathrm{CD}^{+} \%: 12.81 \%$; (D) Gating for CD45 ${ }^{+}$cells; (E) CD14 ${ }^{+} \mathrm{PBMC} \%: 0.95 \%$; (F) CD64 ${ }^{+}$PMN\%:77.28\%; (G) Gating for CD4 $4^{+}$lymphocytes; (H) CD $4^{+} \mathrm{CD} 25^{+} \%: 18.58 \%$; (I) TregCD $4^{+} \mathrm{CD} 25^{+} \mathrm{CD} 127^{+} \%: 8.49 \%$.

\subsection{Detection of serum levels of IL-10 and IL-4}

The serum levels of IL-10 in the MAP patients and SAP patients were $(9.56 \pm 63.50)$ and (10.0 73.43), which did not significantly differ compared with $(8.5 \pm 29.18)$ in the healthy control group (both $P>0.05$ ). No significant difference was observed in terms of the serum levels of IL-10 between the MAP patients and SAP patients $(P>0.05)$. The serum level of IL-4 in the MAP patients was $(8.87 \pm 3.89)$, which was significantly higher compared with $(5.10 \pm 1.93)$ in the healthy controls and $(6.22 \pm 2.12)$ in the SAP patients (both $P<0.05)$, as illustrated in Table 5 . 
Table 5. Comparison of the serum levels of serum IL-10 and IL-4 ( $\bar{x} \pm \mathrm{s})$.

\begin{tabular}{ccc}
\hline Group $(\mathrm{n}=20)$ & IL-10 $(\mathrm{pg} / \mathrm{mL})$ & $\mathrm{IL}-4(\mathrm{pg} / \mathrm{mL})$ \\
\hline Control group & $8.5 \pm 29.18$ & $5.10 \pm 1.93^{\mathrm{a}}$ \\
SAP group & $10.0 \pm 73.43$ & $6.22 \pm 2.12^{\mathrm{a}}$ \\
MAP group & $9.56 \pm 63.50$ & $8.87 \pm 3.89^{\mathrm{b}}$ \\
$F$ & 0.351 & 9.649 \\
$P$ & 0.706 & 0.000 \\
\hline
\end{tabular}

SNK-q test was used for comparison between the two groups; Different letters indicate $P<0.05$ between the two groups, and the same letters represent $P>0.05$ between the two groups.

\section{Discussion}

Recent studies have shown that immune disorders play an important role in the pathogenesis of AP, especially in SAP (Zhang et al., 2009). A meta-study study has pointed out that the discovery of low immune function of network cytokines in the course of AP has attracted widespread attention. During the development of AP into the SIRS pathological stage, inflammatory cytokines are significantly increased, inducing cascade reaction and releasing immunologically-active cells, thus provoking excessive immune response (Yubero et al., 2009). In the later CARS stage, the whole body excessively releases anti-inflammatory mediators, whereas increases the risk of secondary infection and multiple organ dysfunction syndrome (MODS) (Shi et al., 2006). However, how the immune system works during the development of AP has been rarely studied.

Immune response can be divided into the innate and adaptive immune response. Cellular immunity and humoral immunity are vital components of adaptive immune response. $\mathrm{T}$ lymphocytes play a central role in adaptive cellular immune response. CD3 molecule combines with $\mathrm{T}$ cell antigen receptor (TCR) by non-covalent bond to form TCR-CD3 complex, which is a characteristic marker on the surface of all T cells. Mature $\mathrm{T}$ cells can only express either CD4 or CD8. T lymphocytes can be divided into helper $\mathrm{T}$ cells (Th), cytotoxic $\mathrm{T}$ cells $(\mathrm{Tc})$ and regulatory $\mathrm{T}$ cells according to the immune effect function [16]. The imbalance between Th and Tc cells seriously affects the human immune system, which leads to the occurrence and development of AP due to the suppression of the immune level.

In this study, flow cytometry was used to detect the changes of T lymphocyte subsets in the peripheral blood of AP patients and demonstrated that immune dysfunction existed in the course of AP. Immunosuppression increases the chance of bacterial infection, causing secondary infection or MODS, and affecting the clinical prognosis of patients. Compared with healthy controls and MAP patients, the quantity of $\mathrm{CD}^{+}$and $\mathrm{CD}^{+} \mathrm{T}$ lymphocytes in the peripheral blood of SAP patients was significantly reduced. However, there was no significant difference in $\mathrm{CD} 8+\mathrm{T}$ lymphocyte count between AP patients and healthy subjects, which was consistent with the results reported by Kouli et al. (Kou \& You, 2008). The CD4 $4^{+} / \mathrm{CD}^{+}$ ratio of AP patients did not significant differ compared with that of healthy controls, inconsistent with previous findings (Zheng et al., 2010). However, SAP patients were more likely to have the inverted proportion of $\mathrm{CD} 4^{+} / \mathrm{CD}^{+}$ratio than MAP patients and healthy controls, probably related to few cases and different monoclonal antibodies.

$\mathrm{CD} 4^{+} \mathrm{CD} 25^{+} \mathrm{CD} 127^{+}$Treg cells are immunosuppressive cells. Initial $\mathrm{CD} 4^{+} \mathrm{T}$ cells are differentiated under the sole induction of TGF- $\beta$. They have immune incompetence and immunosuppression, of which immunosuppression is closely correlated with the pathogenesis of AP. $\mathrm{CD} 4^{+} \mathrm{CD} 25^{+} \mathrm{CD} 127^{+}$Treg cells can secrete IL-4, IL-10 and TGF- $\beta$ to further inhibit immune function. IL10 and IL-4 are important anti-inflammatory cytokines, which can inhibit Th1 from producing inflammatory factors and effectively inhibit antigen-specific T cell activation (Zheng et al., 2010).

In this study, the expression of $\mathrm{CD} 44^{+} \mathrm{CD} 25^{+} \mathrm{CD} 127^{+}$Treg cells in the peripheral blood of AP patients was detected by flow cytometry, and the levels of IL-10 and IL-4 in the peripheral blood of AP patients were detected by ELISA to explore whether the levels of $\mathrm{CD} 4^{+} \mathrm{CD} 25^{+} \mathrm{CD} 127^{+}$Treg cells, IL-10 and IL- 4 in AP patients were related to the pathogenesis of AP. It was found that compared with the healthy controls, the levels of $\mathrm{CD} 4{ }^{+} \mathrm{CD} 25^{+} \mathrm{CD} 127^{+}$Treg cells and IL-10 in AP patients were not significantly different. However, compared with MAP patients, $\mathrm{CD} 4^{+} \mathrm{CD} 25^{+} \mathrm{CD} 127^{+}$Treg cells in SAP patients were significantly increased. The levels of IL-4 in patients with SAP and healthy controls was significantly lower than that in MAP patients. $\mathrm{CD} 4^{+} \mathrm{CD} 25^{+} \mathrm{CD} 127^{+}$Treg probably suppresses the activation of various inflammatory cells and the pro-inflammatory effects by promoting the secretion of IL-4, and resists the damages caused by excessive inflammatory reaction to the host body. In SIRS phase, excessive inflammatory reaction is the main reaction, and the anti-inflammatory effect of $\mathrm{CD} 4^{+} \mathrm{CD} 25^{+} \mathrm{CD} 127^{+}$Treg cells cannot compete with it. The proportion of $\mathrm{CD} 4^{+} \mathrm{CD} 25^{+} \mathrm{CD} 127^{+}$Treg may increase as the course of disease progresses into CARS. The increase of IL-4 level in early stage of MAP patients indicates that it may enter into the CARS stage, whereas the IL-4 in SAP patients is against inflammatory mediators and has no obvious increase. The profile of IL-10 level was consistent with Rong's findings, where the results of IL- 4 and $\mathrm{CD} 4{ }^{+} \mathrm{CD} 25^{+} \mathrm{CD} 127^{+}$Treg were different from the previous reports (Rong et al., 2010), possibly due to the small sample size and lack of dynamic monitoring of changes in $\mathrm{CD} 4^{+} \mathrm{CD} 25^{+} \mathrm{CD} 127^{+}$Treg and IL-4 levels. With the continuous innovation of treatment methods, more AP patients and even SAP patients can recover quickly after medical standard treatment.

At present, the pathogenesis of AP-induced immune disorders is known as the immune stimulation (Mayerle et al., 2012). During the course of AP, PMN and PBMC exert protective effects on the host body. At different stages of AP development, the changes of immune system are complicated, and the systematic and appropriate balance between SIRS and CARS needs to be further explored. For the progress of AP immunotherapy, it is necessary to better understand different stages of AP and choose the individualized treatment. In addition to the adaptive immune response described above, we also paid attention to the inherent immune response of AP patients. The innate immune cells in human body mainly consisted of neutrophils and monocytesmacrophages. Whether these two kinds of cells promote or suppress the progression of AP remains to be elucidated. 
When AP evolves into the CARS stage, a large number of anti-inflammatory cascade reactions occur. PMN plays a key role in the process of anti-infection. At present, whether the function of PMN will also change along with the variations of immune function remains elusive. The number and function of neutrophils in AP patients have been rarely studied in clinical practice. In this clinical trial, the expression of PMN CD64 in the peripheral blood of AP patients was detected, and it was found that the expression of PMN CD64 in the MAP and SAP patients was significantly higher than that in healthy controls, whereas there was no significant difference in the CD64 expression between the SAP and MAP patients, which were consistent with the inhibition of immune function in CARS stage and the enhancement of PMN's anti-infection function, indicating that PMN's surface markers and functions will change correspondingly with the fluctuations of the body's immune function state. Nevertheless, the results need to be further verified. In this study, the correlation between PMNCD64 and white blood cell count, and the relationship between PMNCD64 expression and the diagnosis of AP diagnosis were not considered.

In the innate immune response, $\mathrm{PBMCs}$ play a role in promoting inflammatory response, processing antigen presentation, initiating adaptive immune response, secreting a large number of factors for immune regulation (Rong et al., 2010). In this investigation, the expression of CD14 $4^{+}$PBMCs in the peripheral blood of AP patients was quantitatively measured, it was found that the expression of CD14 ${ }^{+}$PBMCs in the MAP and SAP patients was significantly lower than that in healthy controls. There was no significant difference in the CD14 expression between the SAP and MAP patients, which was consistent with the results reported by Oiva et al. (2010). The number of PBMCs was decreased and the secretion of pro-inflammatory mediators was also decreased correspondingly, revealing that the PMBC function was inhibited, which severely inhibited the body's immune function and promoted the occurrence and development of AP. The correlation between CD14 and the expression levels of TLR4 and HLR-DA was not considered in the study design. Therefore, the obtained results need to be further verified.

\section{Conclusion}

In terms of the pathogenesis of AP-induced immune disorders, the AP patients present with immune dysfunction. The quantity of $\mathrm{CD}^{+}$and $\mathrm{CD} 4^{+} \mathrm{T}$ lymphocytes, PBMCs and $\mathrm{CD} 4^{+} / \mathrm{CD}^{+}$ratio are significantly reduced in SAP patients. $\mathrm{CD} 4^{+} \mathrm{CD} 25^{+} \mathrm{CD} 127^{+}$Treg probably plays an immunosuppressive role by promoting the secretion of IL-4. During the SIRS phase, the quantity of $\mathrm{CD} 4^{+} \mathrm{CD} 25^{+} \mathrm{CD} 127^{+}$Treg in the SAP patients is significantly higher than that in the MAP patients.

\section{Ethical approval}

The study procedures were approved by the ethics committee of the First Affiliated Hospital of Wannan Medical College Yijishan Hospital. Written informed consents were obtained from all participants prior to study.

\section{Conflict of interest}

The author declare that they have no conflict of interest.

\section{Availability of data and material}

The datasets used or analysed during the current study are available from the corresponding author on reasonable request.

\section{Author contributions}

Qi Wang contributed to experimental studies, data acquisition, data analysis and manuscript editing. Shaofeng Liu and Zhen Han contributed to manuscript editing and review.

\section{References}

Cid, J., Aguinaco, R., Sánchez, R., García-Pardo, G., \& Llorente, A. (2010). Neutrophil CD64 expression as marker of bacterial infection:a systematic review and meta-a-nalysis. The Journal of Infection, 60(5), 313-319. http://dx.doi.org/10.1016/j.jinf.2010.02.013. PMid:20206205.

Döcke, W. D., Randow, F., Syrbe, U., Krausch, D., Asadullah, K., Reinke, P., Volk, H. D., \& Kox, W. (1997). Monocyte deactivation in septic patients: restoration by IFN-gamma treatment. Nature Medicine, 3(6), 678-681. http://dx.doi.org/10.1038/nm0697-678. PMid:9176497.

Fossati, G., Bucknall, R. C., \& Edwards, S. W. (2001). Fcgamma receptors in auto-immune diseases. European Journal of Clinical Investigation, 31(9), 821-831. http://dx.doi.org/10.1046/j.1365-2362.2001.00881.x. PMid:11589725.

Götzinger, P., Sautner, T., Spittler, A., Barlan, M., Wamser, P., Roth, E., Jakesz, R., \& Függer, R. (2000). Severe acute pancreatitis causes alterations in HLA-DR and CD14 expression on peripheral blood monocytes independently of surgical treatment. European Journal of Surgery, 166(8), 628-632. http://dx.doi.org/10.1080/110241500750008286. PMid:11003431.

Kou, L., \& You, S. Y. (2008). Change of T lymphocyte subsets and their different apoptosis in acute pancreatitis. Chin J Hepatob Surg., 14(8), 569-571.

Kylänpää, M. L., Repo, H., \& Puolakkainen, P. A. (2010). Inflammation and immunosuppression in severe acute pancreatitis. World Gastroenterol, 16(23), 2867-2872.

Li, H. G., Zhou, Z. G., Li, Y., Zheng, X. L., Lei, S., Zhu, L., \& Wang, Y. (2007). Alterations of toll-like receptor 4 expression on peripheral blood monocytes during the early stage of human acute pancreatitis. Digestive Diseases and Sciences, 52(8), 1973-1978. http://dx.doi. org/10.1007/s10620-006-9211-4. PMid:17415654.

Mayerle, J., Dummer, A., Sendler, M., Malla, S. R., Van Den Brandt, C., Teller, S., Aghdassi, A., Nitsche, C., \& Lerch, M. M. (2012). Differential roles of inflammatory cells in pancreatitis. Journal of Gastroenterology and Hepatology, 27(Suppl. 2), 47-51. http://dx.doi. org/10.1111/j.1440-1746.2011.07011.x. PMid:22320916.

McNaught, C. E., Woodcock, N. P., Mitchell, C. J., Rowley, G., Johnstone, D., \& MacFie, J. (2002). Gastric colonisation, intestinal permeability and septic morbidity in acute pancreatitis. Pancreatology, 2(5), 463-468. http://dx.doi.org/10.1159/000064712. PMid:12378114.

Nagy, A., Juhász, M. F., Görbe, A., Váradi, A., \& Izbéki, F. (2021). Glucose levels show independent and dose-dependent association with worsening acute pancreatitis outcomes: post-hoc analysis of a prospective, international cohort of 2250 acute pancreatitis cases. Pancreatology, S1424-3903(21), 00478-6.

Oiva, J., Mustonen, H., Kylänpää, M. L., Kyhälä, L., Kuuliala, K., Siitonen, S., Kemppainen, E., Puolakkainen, P., \& Repo, H. (2010). Acute pancreatitis with organ dysfunction associates with abnormal blood lymphocyte signaling: controlled laboratory study. Critical Care, 14(6), R207. http://dx.doi.org/10.1186/cc9329. PMid:21087472. 
Pan, H., Zhou, X. C., \& Peng, X. H. (2012). Expressions of CD14, TLR4 and TNFa in alcohol-induced chronic pancreatitis tissues. World Sci-Tech RedD, 34(3), 478-481.

Pancreas Disease Group of Digestive Disease Branch of Chinese Medical Association. (2013). Guidelines for diagnosis and treatment of acute pancreatitis in China. Chinese Journal of Digestive Diseases, 33(4), 217-222.

Pietruczuk, M., Dabrowska, M. I., Wereszczynska-Siemiatkowska, U., \& Dabrowski, A. (2006). Alteration of peripheral blood lymphocyte subsets in acute pancreatitis. World Journal of Gastroenterology, 12(33), 5344-5351. http://dx.doi.org/10.3748/wjg.v12.i33.5344. PMid:16981265.

Rong, H. S., Wu, H. S., \& Yang, Z. Y. (2010). Dynamic changes of CD4 $+\mathrm{CD} 25$ high regulatory $\mathrm{T}$ cells in peripheral blood of severe acute pancreatitis patients and its significance. Chinese Journal of General Surgery, 25(12), 992-994.

Shi, C., Zhao, X., Lagergren, A., Sigvardsson, M., Wang, X., \& Andersson, R. (2006). Immune status and inflammatory response differ locally and systemically in severe acute pancreatitis. Scandinavian Journal of Gastroenterology, 41(4), 472-480. http:// dx.doi.org/10.1080/00365520500318965. PMid:16635917.
Yubero, S., Ramudo, L., Manso, M. A., \& Dios, I. (2009). Targeting peripheral immune response reduces the severity of necrotizing acute pancreatitis. Critical Care Medicine, 37(1), 240-245. http:// dx.doi.org/10.1097/CCM.0b013e31819320fc. PMid:19050604.

Zhang, X. P., Chen, H. Q., Liu, F., \& Zhang, J. (2009). Advances in researches on the immune dysregulation and therapy of severe acute pancreatitis. Journal of Zhejiang University. Science B., 10(7), 493-498. http://dx.doi.org/10.1631/jzus.B0820265. PMid:19585666.

Zhao, L. S., Zhao, M. F., \& Xie, Y. (2011). Changes of plasma levels of TNF- $\alpha$ and IL- 6 and the expression of TLR4 in peripheral blood mononuclear cell in patients with severe acute pancreatitis and their clinical significance. Journal of Clinical Research, 28(6), 1019-1021.

Zheng, C. B., Zheng, Z. H., \& Zheng, Y. P. (2021). Therapeutic plasma exchange for hyperlipidemic pancreatitis: current evidence and unmet needs. World Journal of Clinical Cases, 9(21), 5794-5803. http://dx.doi.org/10.12998/wjcc.v9.i21.5794. PMid:34368298.

Zheng, X., Li, S. B., \& Wang, Y. (2010). Changes of T lymphocyte subsets before and after treatment of acute pancreatitis and its clinical significance. Xiandai Yixue, 38(4), 395-397. 